\title{
Association of low-frequency currents and crown-of-thorns starfish outbreaks
}

\author{
Kerry Black ${ }^{1, *}$, Peter Moran $^{2}$, Derek Burrage ${ }^{2}$, Glenn De'ath $^{3}$ \\ ${ }^{1}$ Victorian Institute of Marine Sciences, 23 St. Andrews Place, East Melbourne, Victoria 3002, Australia \\ ${ }^{2}$ Australian Institute of Marine Science, PMB No. 3, Townsville MC, Queensland 4810, Australia \\ ${ }^{3}$ James Cook University of North Queensland, Townsville, Queensland 4811, Australia
}

\begin{abstract}
Analyses of 25 yr of coastal currents have revealed slow periods and long-term cycles in longshore current intensity and direction during the annual spawning season of crown-of-thorns starfish. Extraordinary natal larval recruitment during periods of slow, low-frequency longshore currents may be a critical factor associated with primary outbreaks of the starfish on the Great Barrier Reef (GBR). Slow currents result in high local retention of larvae within the eddy-induced well-mixed zone around a reef, with a corresponding potential for abnormally high recruitment back to the natal reef or region. Numerical simulations show that after a crown-of-thorns starfish outbreak is established, large latitudinal sectors of the GBR may be inundated by larvae. Observed southerly progressions of secondary starfish outbreaks were significantly correlated with predicted larval excursions, transmitted by low-frequency currents during spawning seasons. Secondary infestation of reefs, however, could not explain primary events or the noteworthy exceptions in inter-annual outbreak advance along the GBR, suggesting that an outbreak during 1978 at 18 to $19^{\circ} \mathrm{S}$ may have been primary and independent of the earlier events further north.
\end{abstract}

KEY WORDS: Larval dispersal · Numerical models $\cdot$ Recruitment $\cdot$ Continental shelf currents

\section{INTRODUCTION}

The cause of outbreaks of crown-of-thorns starfish on the Great Barrier Reef (GBR) has been the major focus of a long-term research program initiated in 1986 (Zann \& Moran 1988, Lassig \& Kelleher 1992). A series of broad, multi-disciplinary studies have investigated the possible biological, ecological, physical or anthropogenic factors which could stimulate the intense crown-of-thorns starfish outbreaks observed along some $1000 \mathrm{~km}$ of the GBR.

Kenchington (1977) proposed that secondary outbreaks of starfish progressed southward along the GBR after an initial primary outbreak placed unusually large numbers of neutrally buoyant larvae into the

\footnotetext{
- Present address: NIWA and Earth Sciences Department, University of Waikato, PO Box 11-115, Hamilton, New Zealand. E-mail: black@hamilton.niwa.cri.nz
}

water column. Larvae then seeded reefs to the south establishing a 'wave' of outbreaks which passed through the GBR, taking 10 to 12 yr. More recent measurements of currents (Andrews 1983) and detailed starfish observations (Reichelt et al. 1990, Moran et al. 1992) confirmed the southerly drifting hypothesis. Moran et al. (1992) analysed a database of recorded starfish outbreaks to determine the pattern and rate of spread of outbreaks through the GBR and confirmed the 'southern wave' hypothesis. Further evidence was provided by Dight et al. (1990) who incorporated a southerly flow (associated with the East Australian Current) in the boundary conditions of a regionalscale, numerical, hydrodynamic model to depict a net southerly movement of outbreaks.

While Kenchington's hypothesis was able to account for the general pattern of outbreaks observed at that time, some notable anomalies remained unexplained. For example, crown-of-thorns starfish numbers were observed to steadily build up on some reefs several 
years after the main wave had passed through. Moreover, the cause of the primary infestation remained unknown, while inter-annual variability in the currents (sometimes the currents are directed northwards; Burrage et al. 1994) suggested that the general southerly trend may not be valid in each specific pelagic period during early December each year.

Recent numerical modelling has identified important reef-scale phenomena which potentially offer alternative explanations for the anomalies in the pattern of outbreaks. Black et al. (1990) showed that a significant proportion of larvae may remain on or near the natal reef; the numbers retained exhibited a strong dependence on current strength during the critical 2 to 4 wk pelagic period (Black et al. 1990, Black 1993). This research suggests that the variation in water currents around reefs may have a profound effect on the patterns of recruitment of marine organisms. Food supply, predation and recruitment success must each have a regulatory role, and Birkeland (1982) has suggested that enhancement of larval food supply from nutrient-enriched terrestrial run-off may also be important. However, pelagic larval numbers available for local settlement rise significantly during periods of slow, low-frequency currents and may temporarily override other recruitment controls to allow establishment of an outbreak when food supply is plentiful.

Previous studies of the relationship between water currents and crown-of-thorns starfish outbreaks have been unable to consider the low-frequency variations in the highly energetic East Australian currents within the GBR. The present study compares observed outbreak movements with those predicted using a recently developed time series of low-frequency currents over 25 yr (Burrage et al. 1994). The largest relevant spatial scale, encompassing the Central and Cairns sections of the GBR, over the longest possible time scale of 25 successive years of starfish observations is examined to provide the first deterministic analysis of the hydrodynamic conditions which may be implicated as a cause of starfish outbreaks.

Due to limitations in data, particularly with respect to recorded primary outbreaks, assumptions about spatial current variation, starfish life cycle and crown-ofthorns starfish outbreak durations still had to be made and the statistical significance of the link between current strength and primary outbreaks could not be determined. The study, however, shows that extraordinary natal larval recruitment is implicated as a mechanism for outbreaks; and, a statistically significant correlation between predicted annual larval excursions and the recorded speed of the wave of secondary outbreaks was obtained.

\section{METHODS}

Hindcast currents. Hindcast time series of currents were developed for 5 sites across the continental shelf off Townsville, Australia, in the Central region of the GBR (Burrage et al. 1994). In essence, the predictions used the observation that longshore coastal currents on the continental shelf were geostrophic $c_{i}$ the current intensity being proportional to the set-up or set-down in coastal sea levels at the permanent tidal station at Townsville (Burrage et al. 1994).

A series of corrections were applied to eliminate sea level oscillations unrelated to current strength. The Townsville sea level was low pass filtered (half power point at $51.4 \mathrm{~h}$ ) and corrected for atmospheric pressure variation. To obtain the cross-shelf gradient, a $90 \mathrm{~d}$, running-mean-smoothed time series of sea level recorded at Noumea, French Polynesia, was subtracted from the Townsville levels. This eliminated unwanted seasonal oscillations of the western Pacific basin, which are unrelated to geostrophic continental shelf currents.

For this paper, we use the 25 yr time series of middepth currents at Site B (Fig. 1). The site, located near $19^{\circ} \mathrm{S}$ in the GBR inner lagoon north of Townsville, is considered representative of continental shelf currents within and shoreward of the reef matrix throughout our region of interest. This is supported by

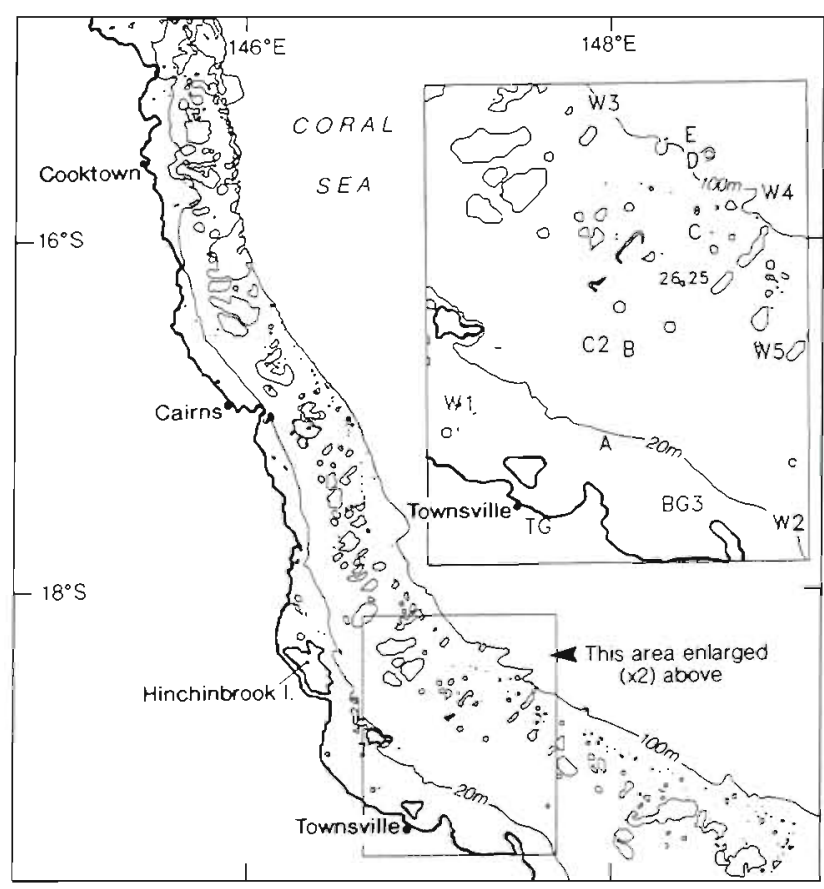

Fig. 1 Great Barrier Reef and Central Section measurement sites (W1-W5: near-bottom mounted pressure sensor; A-E, C2, BG3: currents; TG: tide gauge) 
a number of independent lines of evidence. Burrage (1993) and Burrage et al. (1995) reported that nearsurface currents observed at a long-term mooring on the upper continental slope at $14^{\circ} \mathrm{N}$ show that the southward-flowing East Australian Current originates near this location. This current forces a prevailing southward flow downstream, along the outer GBR. Preliminary analyses of current measurements and sea levels at Green Island near $17^{\circ} \mathrm{S}$ (Stevens et al. 1992) show that the linear relationship between currents and sea levels identified by Burrage et al. (1994) holds near the Island with only minor changes in the regression parameters. In addition, analyses of sea level fluctuations along the GBR have shown northward propagating continental shelf waves which remain coherent between latitudes 22 and $11.6^{\circ} \mathrm{S}$ with time lags of $4.5 \mathrm{~d}$ over the $1200 \mathrm{~km}$ range (Fig. 5.5 of Wolanski 1994). This zone encompasses the region of starfish outbreaks being considered here $\left(14\right.$ to $\left.21^{\circ} \mathrm{S}\right)$. Thus, while spatial variations in current intensity will occur through the region of interest, the relative strengths of the flows (represented by the time series at Site $B$ ) remain coherent. The relationship of currents at Site B to locations across the shelf in the central GBR is summarised by Burrage et al. (1994). The variance on the offshore edge of the reef matrix is similar to Site $B$ but the mean current is more negative (southerly) by 8 to $9 \mathrm{~cm} \mathrm{~s}^{-1}$. As the flows at Site B are unimpeded by nearby reefs, they reflect the regional current strength and are not influenced by local reef-scale circulation.

Burrage et al. (1994) found that the maximum standard error of the hindcast currents at Site B was $9.7 \mathrm{~cm}$ $\mathrm{s}^{-1}$ while the maximum bias (with the seasonal correction) was $3.3 \mathrm{~cm} \mathrm{~s}^{-1}$. Digitised sea levels were available for Townsville and Noumea from 1966 and 1976 respectively. Thus, we have less confidence in predictions of currents from 1966 to 1975, inclusive, which do not incorporate the Noumea correction and for which the maximum bias becomes $15.7 \mathrm{~cm} \mathrm{~s}^{-1}$.

Crown-of-thorns starfish database. We extracted from a database all starfish sightings and outbreaks (Moran et al. 1992). Some 84 reefs were identified during the first period of outbreaks from 1965 to 1978 and 97 reefs during the second period from 1978 to 1990 . The extracted database comprised the dates and locations of the first reliable sightings of outbreaks on each of these reefs.

The dates were standardised to the estimated 'year of initial larval recruitment to the reef' based on (1) mean diameter of the starfish when first observed, (2) amount of live and dead coral observed and (3) starfish abundance recorded in later periods. This information was placed in context by comparisons with field observations of a developing outbreak at
John Brewer Reef (Moran et al. 1985), a mid-shelf reef located in the large Central section of the GBR. Where no information was available, it was assumed that the starfish were 3 to $4 \mathrm{yr}$ old; this was based on the relationship between size and age from field surveys (Zann et al. 1990) and the average size of starfish in outbreaks as detected by the manta tow technique.

Due to variations in development rate and size/age ratios (Zann et al. 1990), some errors in recruitment dates are expected. However, the standardised initial recruitment dates are expected to be more coherent than the unstandardised times when outbreaks were first observed which have no common time origin. The pattern and progression of outbreaks obtained by using the individually established dates of initial recruitment is different from that obtained by using the date of the first sighting of the outbreak as applied by Moran et al. (1992). Notably, all dates in this paper relate to the standardised year, i.e. the year of larval recruitment to the reef.

Most commonly, adjustments of 3 to 4 yr were made, although the adjustments varied as much as 2 to $6 \mathrm{yr}$. As no useful size information was available for the first series of outbreaks, all of these dates were standardised by assuming the starfish were 3 to $4 \mathrm{yr}$ old. We therefore have less confidence in the earlier dates (and less confidence in the first 10 yr of hindcast currents), so the main conclusions in this paper are drawn from the second series of outbreaks.

Spawning period and pelagic duration. The most likely time for spawning is during the first $2 \mathrm{wk}$ of December (Lucas 1973, Babcock \& Mundy 1992). While spawning has been observed as late as mid January (Babcock \& Mundy 1992), laboratory tests and unpublished field experiments (Benzie \& Dixon 1994, R. C. Babcock pers. comm.) suggest that survivorship of these late larvae may be greatly reduced. For completeness, we included the 'extended' 6 wk spawning period from December 1 to January 12 in addition to the 'likely' period from December 1 to 14 .

Laboratory experiments have indicated that starfish larvae mostly settle after $14 \mathrm{~d}$, but the settlement time could be as short as $10 \mathrm{~d}$ or as long as $28 \mathrm{~d}$ (Olson 1987, Olson \& Olson 1989). As such, we considered 10, 14 and $28 \mathrm{~d}$ periods to test the sensitivity of the results to the duration of the pelagic phase. To examine the currents during the period critical for the larvae, we extracted from the 25 yr time series (Fig. 2) the currents during the extended spawning period plus $28 \mathrm{~d}$ for the maximum pelagic duration (i.e. 10 wk from December 1). Gaps in the Townsville sea level record resulted in gaps in the velocities during the 1977/1978, 1979/1980,1980/1981 and 1981/1982 seasons. 

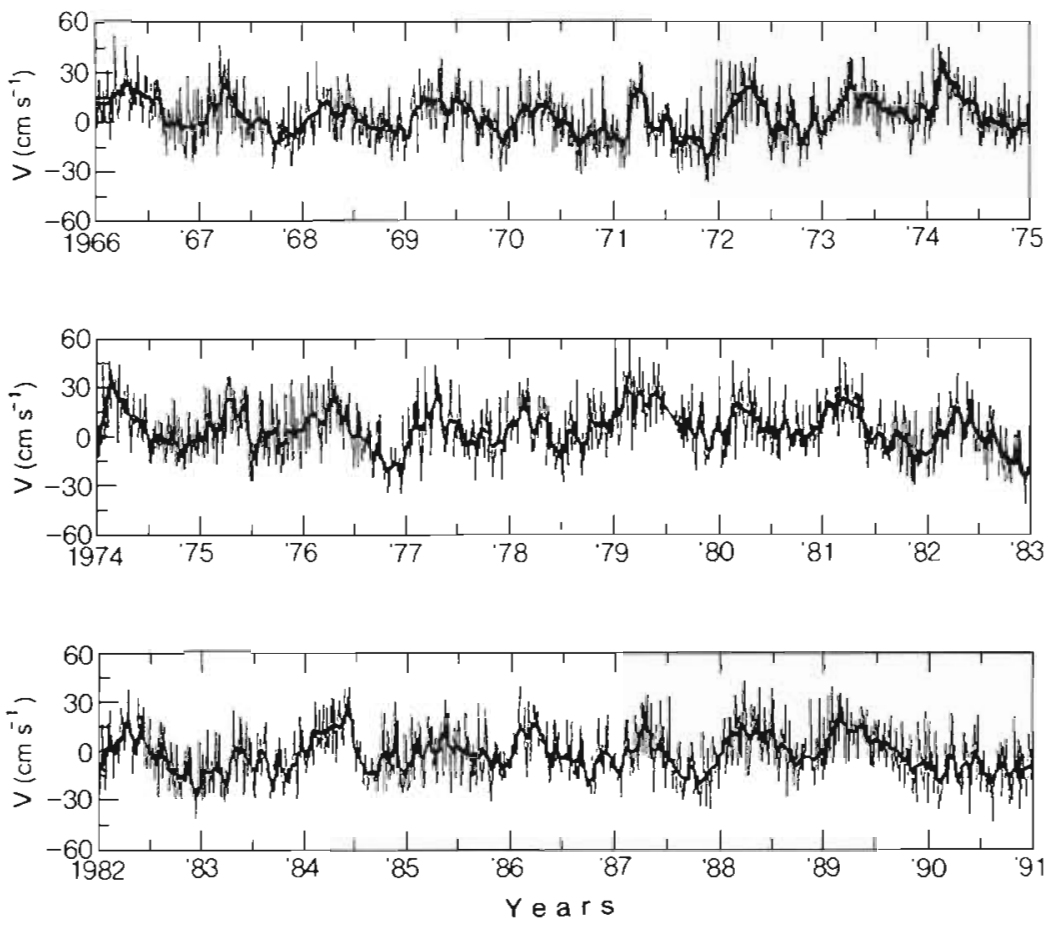

Fig. 2. Hindcast $25 \mathrm{yr}$ time series of currents at Site B in the inner lagoon of the central GBR

\section{RESULTS}

\section{Currents and potential larval excursions}

Both seasonal and inter-annual variability typifies the 25 yr time series of longshore currents at Site $B$ (Fig. 2). Low-frequency currents of around $0.3 \mathrm{~m} \mathrm{~s}^{-1}$ are common. The seasonal trend matches the seasonal directional shift in the trade winds. The inter-annual variations are associated with the El Niño Southern Oscillation and variations in local weather patterns (Burrage et al. 1994).

The flows during the critical spawning and pelagic period are also characterised by variability (both during the $10 \mathrm{wk}$ time series and inter-annually) with positive (equatorward) and negative velocities of up to about $40 \mathrm{~cm} \mathrm{~s}^{-1}$ (Fig. 3). Reversing meteorologically induced oscillations with 7 to $14 \mathrm{~d}$ periods predominate.

Potential larval excursions are shown in Fig. 4. These are the total displacements after the pelagic phase for a succession of initial times at $6 \mathrm{~h}$ intervals throughout the spawning periods (Fig. 4). Variability is still common. For example, during 1978, the excursion of larvae released at the beginning of December was close to $0 \mathrm{~km}$ while the excursion of late larvae was about 400 $\mathrm{km}$ (Fig. 4). However, periodicity is evident, with the largest period being about $15 \mathrm{yr}$ (maximum southbound currents around 1970 and 1985), and there are many years where only large or small drifts occur. Consequently, large negative excursions (to the south) recur in 1969 to $1971,1976,1982,1984,1989$ and 1990 (Fig. 4). Very small larval excursions recur around 1966, 1974 . $1975,1977,1978,1983$ and 1986 to 1988 and, although the net current is to the south on the GBR, positive (northerly) excursions remain common, e.g. $1968,1973,1978$ to 1980 , 1983 and 1988.

Fig. 4 shows that the timing of spawning influences net larval excursion, although there is no evidence to suggest that starfish have the ability to time spawning to coincide with periods of slow longshore currents. While some uncertainty in the initial spawning time remains (starfish spawn several times during a season), the interannual variability in larval excursions is seen to be cyclic, so there are years when excursions are small and natal recruitment or local regional recruitment is more likely. This phenomenon is central to the interpretation of the cause of initial outbreaks (see 'Discussion'). The intraannual variation is superimposed on the longer periodicity. The analyses depict all possible intra-annual variations by calculating the net movement at $6 \mathrm{~h}$ intervals throughout the full spawning season. While large or small net excursions can occur in some years, depend-

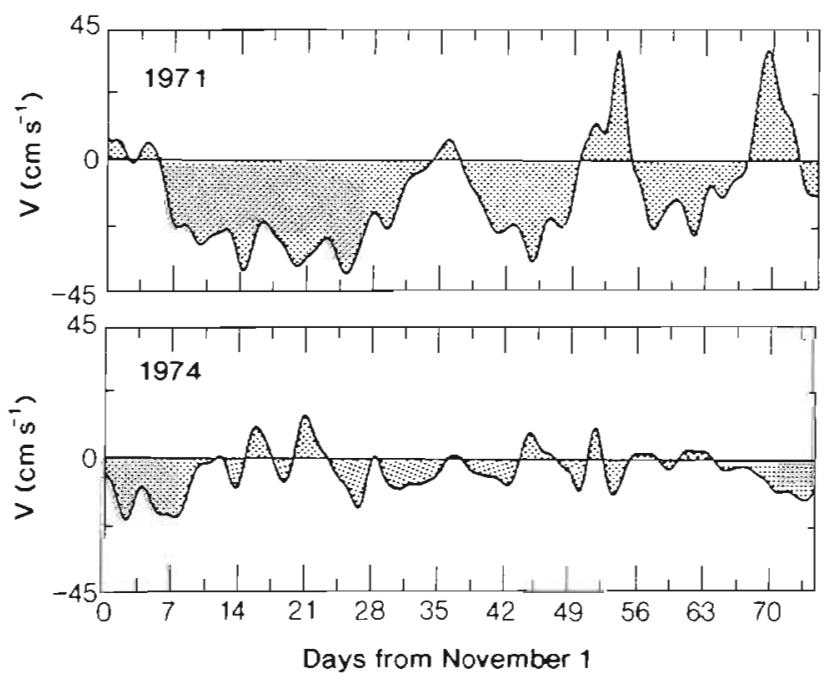

Fig. 3. Hindcast longshore currents over the $10 \mathrm{wk}$ period from November 1 in 1971 and 1974 at Site B. Fast currents and high variability typify 1971 while currents are slow in

1974. The likely spawning period starts on December 1 


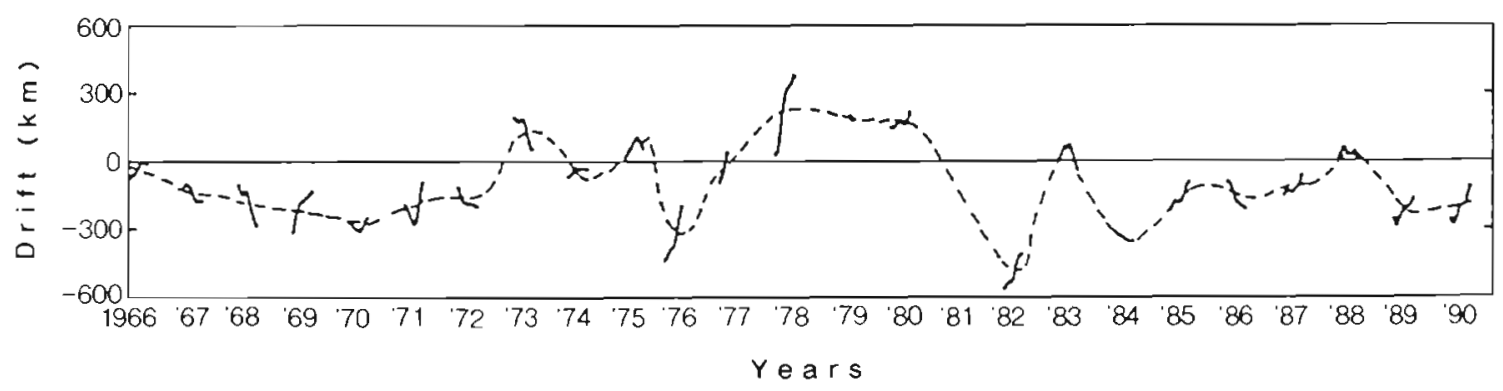

Fig. 4. Dispersal drift excursions for the likely spawning period from December 1 to 14 for a $28 \mathrm{~d}$ pelagic dispersal period (1966 to 1990 )

ing on the initial spawning time, the lowest-frequency inter-annual cycle with a 15 yr period predominates.

For the likely spawning period, long-term, interannual cyclic trends in the direction and magnitude of the excursion are clearly evident (Fig. 4). These trends result in a long-term oscillation in the excursion distances which may be related to variations in natal and inter-reef recruitment.

\section{Comparison with crown-of-thorns starfish database}

To compare predicted excursions with starfish outbreaks, a simple (spatial) particle advection model was developed. 'Spawned larvae' were represented by free-drifting particles released once every day during the spawning period from each 'source' reef and advected with the hindcast currents parallel with the coast. (Coastal orientation was taken from a bathymetric chart.) A source reef was one containing 'mature adult starfish'. An analysis of the starfish database indicated that the average time during which mature adult populations were in outbreak proportions decreased with the intensity of the outbreak. The duration was as little as $1 \mathrm{yr}$ when outbreak populations exceeded 27000 starfish $\mathrm{km}^{-2}$, while for a typical high density case the duration averaged $1.25 \mathrm{yr}$. A mild outbreak (2068 starfish $\mathrm{km}^{-2}$ ) lasted about 4 yr. Thus, 2 cases were tested: a 2 yr viable period with adults 2 to $3 \mathrm{yr}$ old and a 4 yr viable period with adults 2 to $5 \mathrm{yr}$ old. No significant difference with respect to the southerly progression between the 2 cases was identified and so only the 4 yr case will be discussed.

For the following analyses, the size of the populations on the outbreak reefs did not have to be differentiated, as absolute numbers of larvae were not being considered. The currents were taken to be equal in magnitude to those predicted at Site B throughout the region of interest $\left(14\right.$ to $\left.21^{\circ} \mathrm{S}\right)$. The currents are coherent over these spatial scales but some longshore and cross-shore variability in the current intensity is expected. Only one question is to be addressed by the particle advection model, i.e. can the year-by-year migrations and patterns of observed outbreaks be explained by secondary outbreak due to waterborne pelagic dispersal?

Fig. 5 shows the latitudes of the final positions of the particles after the pelagic phase, together with the latitudes of the source reefs and outbreak reefs for each year. Several cases were considered: 10,14 and $28 \mathrm{~d}$ pelagic periods and the likely and extended spawning periods. Fig. 5 shows the $10 \mathrm{~d}$ likely-spawning-period case.

The predicted cloud of particles mostly attains or exceeds the latitude of the outbreak reefs. Thus, in general, the results support both the southerly wave hypothesis and the less pronounced northerly movement starting from the outbreak epicentre around $16^{\circ} \mathrm{S}$ (Moran et al. 1992). To assess the statistical significance of the results, Fig. 6 shows the actual southerly progression of outbreak reefs (taken as the maximum distance annually in degrees of latitude from the southernmost source population to the southernmost new outbreak) plotted against the maximum predicted excursion. Cases of southerly transport and new outbreaks were treated. These were years 1966 to $1970,1975,1977$ to 1978 and 1980 to 1985 , where all values were inclusive. 1986 was neglected because only one new outbreak reef was identified after the outbreaks had passed through the region and exhausted the food supply.

With all remaining data included, a non-significant correlation coefficient of $r=0.18(n=14, p=0.269)$ was obtained between the actual and predicted excursions. With 1975 neglected, the correlation coefficient increased to $\mathrm{r}=0.29(\mathrm{n}=13, \mathrm{p}=0.167)$ but remained non-significant. With 1978 neglected, the correlation coefficient increased to $r=0.59(\mathrm{n}=12, \mathrm{p}=0.021)$ which, at the $p=0.025$ level, is now significant (Fig. 6).

Thus, with the exception of the anomalous years 1975 and 1978, the year-by-year migrations and pat- 


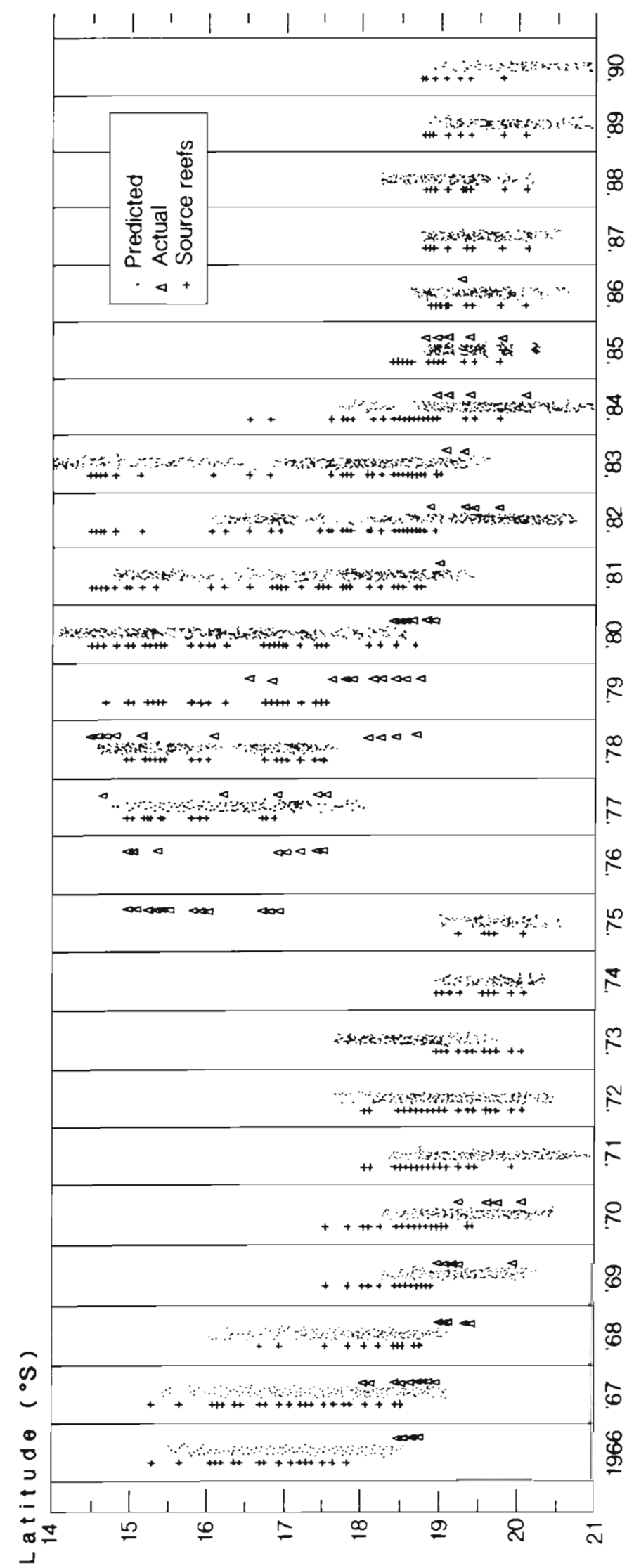

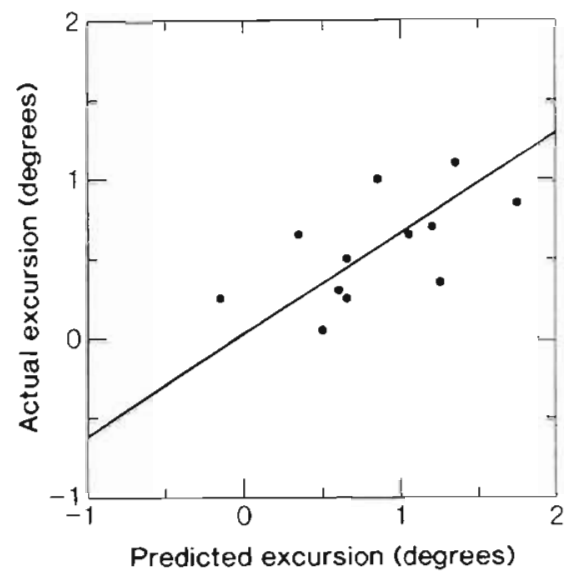

Fig. 6. Observed southerly progression of outbreaks versus the excursion predicted by the particle advection model, with 1975 and 1978 data excluded. Gradient and intercept of the best fit line are 0.63 and 0.021 respectively with $\mathrm{r}^{2}=0.35$

terns of observed outbreaks can be explained by secondary outbreak due to waterborne pelagic dispersal. More specifically, the statistical significance indicates that currents on the GBR explain the 'southern wave' of outbreaks from the epicentre around $16^{\circ} \mathrm{S}$. While 1975 is the year when primary outbreaks began in the north, and so its omission as a secondary outbreak anomaly could be expected, the model provides no explanation for these anomalous primary outbreaks around 1975, nor for the progression of the outbreaks from $17.5^{\circ} \mathrm{S}$ in 1977 to 18 to $18.5^{\circ} \mathrm{S}$ in 1978 .

\section{Primary outbreaks}

Small net excursions can occur even when currents are fast. Thus, to quantify self-seeding potential during the spawning seasons, we have applied the formulae of Black et al. (1990) to calculate the percentage of larvae retained around a reef as a function of current conditions and reef size. This solution integrates the net retention of larvae over the spawning season as a function of current intensity. For a given reef, high retention is associated with slow currents over the full pelagic period.

Fig. 5. Predictions after a $10 \mathrm{~d}$ pelagic period of larval excursion with source reefs and actual outbreak reefs for each year from 1966 to 1990 . Dates are standardised to the dates of initial recruitment of larvae. For example, 1974 is associated with the December to January (1974/ 1975) season 
For an initial number of larvae $N_{0}$, the number remaining at time $t$ is

$$
N=N_{0} \mathrm{e}^{-B t}
$$

where $B$ is the decay coefficient which depends on current strength and reef dimensions (Black et al. 1990) For the variable currents being considered, Eq. (1) was integrated numerically. Reef dimensions and tidal excursion were selected to represent John Brewer Reef in the central GBR which is situated close to Site B. The Site B currents for each year were used to calculate the percentage of larvae retained on the natal reef after 10,14 and $28 d$, at daily intervals throughout the likely and extended spawning periods.

For both the 14 and 28 d pelagic periods and for both the likely and extended spawning periods, the highest retention occurs in 1978 and 1974 respectively (Fig. 7). A peak in 1975 is evident if a $14 \mathrm{~d}$ pelagic period is assumed. Thus, the latest 'wave' of outbreaks on the GBR began after currents were exceptionally slow in the early to mid 1970s, particularly around 1974/1975 (Fig. 4). The analysis indicates high natal recruitment at these times (Fig. 7).

The analysis of $25 \mathrm{yr}$ of currents has shown that lowfrequency variation in the longshore currents on the GBR occurs at decadal time scales. This establishes the propensity for occasional years when currents are exceptionally slow during the critical pelagic phase of the crown-of-thorns starfish larvae. Slow currents result in high local retention of larvae around individual reefs (Black et al. 1990) and abnormally high recruitment may result.

On the contrary, in high currents larvae are spread over a much wider region and, due to hydrodynamic factors, are less likely to successfully recruit (downstream) than the larvae which remain on a natal reef (Black 1993). High recruitment to a single reef (or reefs) may be subsequently compounded by higher fertilization success in high-density, clustered populations in succeeding years (Babcock et al. 1994, Benzie \& Dixon 1994).

The 1978 outbreak in the northern zone of the large Central section of the GBR (about $150 \mathrm{~km}$ south of Green Island) may have been primary, rather than secondary, because the larval excursion results show no secondary larval input to this region (Fig. 5). Moreover, the analysis of larval retention shows 1978 to have an exceptionally high selfseeding potential. Notably, $35 \%$ of larvae are predicted to remain on the natal reef after $14 \mathrm{~d}$ in 1978 . Some $4 \%$ are still present after $28 \mathrm{~d}$. John Brewer Reef is a small to medium sized reef and more lar- vae should be retained by the larger reefs on the GBR (Black et al. 1990).

While there are some uncertainties about spawning times and starfish ages, these do not change the conclusion that the 1978 outbreak may have been primary. The outbreaks recorded in 1977 and 1978 are drawn from the first of a detailed series of surveys (Moran et al. 1988) and are therefore expected to be reliable. The 1978 anomaly occurs for a 10,14 or 28 d pelagic phase, irrespective of whether the likely or extended spawning period is considered. The net currents are clearly near zero or northerly during 1978 while the outbreaks apparently progress south. We have confidence in the hindcast currents at this time as the Noumea seasonal correction has been applied. Moreover, the currents are applicable because Site B is situated at $18.8^{\circ} \mathrm{S}$ which is very near the region being considered. The filter applied to the currents (with 51.4 h half power point) eliminates short-term fluctuations but these are not expected to be able to reverse the net northerly trend to create a strong net southerly migration.

The slope of the regression line indicates that the particle advection model tends to overestimate the excursion distance (Fig. 6). This may be related to physical factors which were not included in the model. First, larvae take a finite time to escape from the natal reef (Black et al. 1990) and this time delay has not been included in the simple advection model. Second, the influence of the reefs themselves has been neglected. Small-scale modelling has shown that reefs trap some passing larvae, thereby causing the speed of the centre of mass of a patch to be reduced (Black 1993) while the reefs themselves cause the low-frequency flow to be reduced within the reef matrix. Thus, predicted excursions will be representative of those larvae which do not interact with individual reefs, and are therefore likely to be maximum distances. This means, however, that the 1978 anomaly cannot be readily explained by an overestimate of larval translation by the model.

Some uncertainty in the date of initial recruitment remains due to uncertainties in the age/size relation-

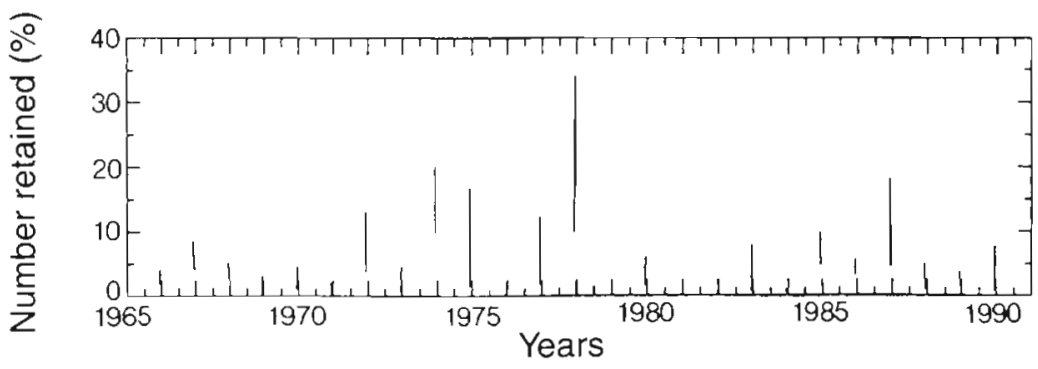

Fig. 7. Predicted self-seeding particle retention around John Brewer Reef after a $14 \mathrm{~d}$ pelagic period. Particles were released during the likely spawning period. Bars show the spread of possible retention percentages for each initial release time 
ship (Zann et al. 1990). Moreover, a gap in the 1979 record prevents a full assessment of potential larval inputs 1 yr before and after 1978, although the available records suggest mostly slow or northerly currents in both 1977 and 1979 (Fig. 4) and, therefore, these currents do not explain the southerly progression. Fig. 5 shows larvae going no further than $18^{\circ} \mathrm{S}$ until 1980. There remains some chance that the spawning season occurred earlier in 1978. However, an inspection of the currents in November 1978 before our initial release time showed that slow currents occurred during this period also. Thus, the existing evidence suggests that the 1978 outbreak may have been primary.

\section{DISCUSSION}

Causal links between hydrodynamics and recruitment of marine species have been identified previously (e.g. Bailey 1981, Roughgarden et al. 1988, Goodrich et al. 1989, Farrell et al. 1991, Little \& Epifanio 1991), and some of these authors argue for local retention as a general mechanism of enhanced larval recruitment. Within the starfish research program, numerical models of currents have been used to predict spatial variation in settlement of crown-of-thorns starfish at an individual-reef and reef-group scale (Black \& Moran 1991) and at a continental-shelf scale (Dight et al. 1990). Reef-scale spatial variation was associated with a complex system of 'phase eddies' which develop on the GBR due to unsteadiness in the tidal circulation around coral reefs (Black \& Gay 1987).

Similarly, temporal variation in recruitment has been associated with variation in the physical factors which generate currents. For example, intra-annual variation in barnacle recruitment in California, USA, was found to be related to the relaxation of onshore winds and consequent cessation of coastal upwelling (Farrell et al. 1991). Jenkins \& Black (1994) have identified an interaction of various current components which results in temporal variation in recruitment of King George whiting in a large bay in southern Australia.

Low-density populations of starfish throughout the GBR (Moran 1986, Moran et al. 1988, Moran \& De'ath 1992) must cumulatively provide the vital contribution to the larval pool for continuation of the species. However, there are no obvious explanations of how these low-level populations continue at the same small site from one generation to the next if secondary infestation provides the only larval supply. The inter-annual variability in the currents alone should be sufficient to prevent the exact transfer of larvae from an upstream site to a restricted region on a particular downstream reef (Dight et al. 1990).
Thus, a universal theory must provide general explanations for 3 phenomena: (1) the long-term presence of low-level populations on reefs, (2) the initiation of a primary outbreak, and (3) the secondary infestation of downstream reefs. With reference to the first phenomenon, Black \& Moran (1991) noted that initial outbreak locations on individual reefs were correlated with zones where the hydrodynamics cause relatively higher local recruitment. This focussing of larvae may allow small populations to seed the natal region.

At the smallest scales, studies of the dispersal of starfish larvae over distances of metres (Babcock et al. 1994, Benzie et al. 1994) have suggested that microscale processes, such as the interaction of the larvae with the sea bed topography, need to be considered to fully characterise the potential range of larval excursions for a given pelagic organism. Benzie et al. (1994) recorded crown-of-thorns starfish eggs entering the substrate within minutes of their release, even though the pelagic duration of a freely drifting gamete may be as long as $28 \mathrm{~d}$. These observations of eggs entering the substrate near the spawning starfish suggest highly localised recruitment as a mechanism to explain the presence of several generations of low-level populations on some reefs (Benzie et al. 1994).

In this paper, the particle advection model has shown that secondary infestation can generally explain the observed movement of outbreaks. A significant correlation between the model and the outbreak progression was obtained at the $p=0.025$ level of significance. Thus, a deterministic relationship between currents and outbreaks has been identified. Exceptions which could not be explained by secondary infestation were the initial primary outbreaks in the early 1960 s and 1975. An anomalous southerly movement of outbreaks in 1978 was also found to be unexplained by secondary infestation. Each of these anomalies occurred when currents were consistently slow during the spawning period, implicating extraordinarily high natal recruitment as the trigger which allowed the outbreaks to develop.

Several factors may assist the development of primary outbreaks. Undoubtedly, food supply controls starfish populations, particularly during and after a major outbreak. This is evident in Fig. 5 when no new outbreaks occur in the north after the initial infestation becomes established in 1978 even though larval supply remains plentiful.

Predation and other causes of larval loss are also likely to be important, but the level of predation may not vary sufficiently inter-annually to allow the predatory control to be reduced to a level where outbreaks can suddenly get under way. In addition, predation may be a less significant controlling factor during years with higher numbers of (self-seeding) recruits. Using 
numerical stock-recruitment simulations, McCallum (1992) found that starfish populations may be greatly affected by very minor variations in the amount of larval interchange between reefs, even small changes in the amount of background recruitment which may be too small to measure. Thus, while the predation levels may be relatively stable, small changes in larval recruits due to variation in currents may have significant consequences for recruitment success.

Several important questions remain untreated. For example, why do the initial outbreaks appear in the Cairns to Cooktown region? Average currents may be slower in the Cairns to Cooktown region because of the barrier provided by the offshore ribbon reefs. This region is closer to the bifurcation of the East Australian Current which approaches the coast north of Cairns and bifurcates north and south (Church 1987), so net currents within the bifurcation region may be smaller than elsewhere. Other distinguishing features could relate to temperature (Black 1992), salinity, food supply, predator numbers, etc., which may determine larval survivorship. Each of these factors may accumulate to establish the environment which allows an outbreak to begin more easily in the Cairns to Cooktown region, and suitable recruitment years (e.g. when currents are slow) may precipitate an outbreak. Further studies will be needed to attempt to define any differences between the regions relevant to starfish outbreaks

While the southern wave hypothesis generally identifies $16^{\circ} \mathrm{S}$ as the initial epicentre of outbreaks (Moran et al. 1992), if the 1978 outbreak is primary then there may be no difference between the regions, as primary outbreaks have developed separately in both. This would mean that the 2 regions are similar in character but out of phase with respect to the initiation of outbreaks. Moran et al. (1992) identified a similar case in the southern GBR where outbreaks in the Swain Reefs appeared to occur prior to the arrival of the 'southern wave' of larvae.

The progressions of the 2 outbreak events are remarkably qualitatively similar (Fig. 5). Once again, outbreaks between 18 and $19^{\circ} \mathrm{S}$ in 1966 are not fully explained by secondary infestation, particularly if the model tends to overestimate the larval excursions. Unfortunately, hindcast currents prior to 1966 were not readily available, while both the starfish database and the hindcast currents are less reliable between 1966 and 1975 than in the subsequent years.

While slow currents in 1975 and 1978 have been considered, Fig. 7 also shows a series of additional slow current years such as 1974 and 1987. If the dating of initial recruitment was in error by $1 \mathrm{yr}$, then the currents in 1974 may indeed be related to a high larval recruitment pulse which initiated the outbreaks con- sidered to have commenced in 1975. In 1987, outbreak populations from only 4 yr earlier in 1983 were still present on northern reefs. Thus, limited food supply may have prevented a new outbreak developing around 1987 when currents were slow.

The standardised dates of initial recruitment spread the initial outbreaks from 15 to $17^{\circ} \mathrm{S}$ in 1975 (Fig. 5). Our knowledge of the weather variation and longshore variation in the East Australian Current suggests that slow currents occur simultaneously over a relatively large region of the GBR. Thus, widespread retention of larvae could be expected to occur on a regional scale.

After an outbreak is established, the particle advection model indicates that large regions of the reef are often inundated with larvae (Fig. 5). This is particularly evident near the end of the outbreaks when adult starfish are widely scattered and producing larvae, e.g. in 1983 when larvae extend from 14 to $19.5^{\circ} \mathrm{S}$ (Fig. 5). This inundation essentially blankets large regions of the GBR, suggesting that source/sink relationships (Dight et al. 1990) may be partially obscured during these times. Potential management of the outbreaks is confounded by the wide initial distribution and is made even more difficult if the outbreak in the large Central region in 1978 is an independent primary event.

In addition, the modelling indicates that the total number of available recruits changes considerably inter-annually. The number of particles found throughout the modelled region can be very low or very high in any given year, primarily due to the number of seeding reefs with outbreaks. The density of the particles also tends to vary latitudinally. Larval input on a yearby-year basis, therefore, will be highly variable at each location.

In conclusion, a 25 yr times series of currents in the central GBR has been used to examine the causes and distinguishing features of primary and secondary outbreaks of crown-of-thorns starfish. Predictions of the large-scale movement of starfish larvae during 2 series of outbreaks from 1966 to 1990 showed that the Kenchington 'southern wave' hypothesis of waterborne larval transfer explains much about the progression and pattern of the secondary outbreaks. Primary outbreaks were observed after periods of slow current including an anomalous outbreak in the central Great Barrier Reef in 1978.

Acknowledgements. This work was funded by the Crownof-Thorns Starfish Research Committee (COTSREC), Australian Institute of Marine Sciences and Victorian Institute of Marine Science. The authors thank Brian Lassig, Craig Steinberg, Kevin Ness, David Hatton, Mark Rosenberg and Peter Greilach for their assistance during the program. The paper is dedicated to retired COTSREC chairman Prof. John Swan. 


\section{LITERATURE CITED}

Andrews JC (1983) Lagoon-ocean interactions. In: Baker JT (ed) Proceedings of the inaugural Great Barrier Reef Conference. JCU Press, Townsville, p 403-408

Babcock RC, Mundy CN (1992) Reproductive biology, spawning and field fertilization rates of Acanthaster planci. Aust J mar Freshwat Res 43:39-52

Babcock RC, Mundy CN, Whitehead D (1994) Sperm diffusion models and in situ confirmation of long-distance fertilization in the free-spawning asteroid Acanthaster planci. Biol Bull 186:117-128

Bailey KM (1981) Larval transport and recruitment of Pacific hake Merluccius productus. Mar Ecol Prog Ser 6:1-9

Benzie JAH, Black KP, Moran PJ, Dixon P (1994) Small-scale dispersion of eggs and sperm of the crown-of-thorns starfish (Acanthaster planci) in a shallow coral reef habitat. Biol Bull 186:153-167

Benzie JAH, Dixon P (1994) The effects of sperm concentration, sperm:egg ratio, and gamete age on fertilization success in crown-of-thorns starfish (Acanthaster plancl) in the laboratory. Biol Bull 186:139-152

Birkeland C (1982) Terrestrial runoff as a cause of outbreaks of Acanthaster planci (Echinodermata: Asteroidea). Mar Biol 69:175-185

Black KP (1992) The temperatures and water currents of the Great Barrier Reef during crown-of-thorns starfish outbreaks since 1966. Report to the Great Barrier Reef Marine Park Authority. Victorian Institute of Marine Sciences Report, Melbourne

Black KP (1993) The relative importance of local retention and inter-reef dispersal of neutrally buoyant material on coral reefs. Coral Reefs 12:43-53

Black KP. Gay SL (1987) Eddy formation in unsteady flows. J geophys Res 92(C9):9514-9522.

Black KP, Gay SL, Andrews JC (1990) Residence times of neutrally-buoyant matter such as larvae, sewage or nutrients on coral reefs. Coral Reefs 9(3):105-114

Black KP, Moran PJ (1991) Influence of hydrodynamics on the passive dispersal and initial recruitment of larvae of Acanthaster planci (Echinodermata: Asteroidea) on the Great Barrier Reef. Mar Ecol Prog Ser 69:55-65

Burrage DM (1993) Coral Sea currents. Corella 17(3):135-145

Burrage DM, Black KP, Ness KF (1994) Long-term current prediction in the central Great Barrier Reef. Cont Shelf Res 14(7/8):803-829

Burrage DM, Hughes RD, Bode L, Williams DMcB (1995) Dynamic features and transports of the Coral Sea circulation. In: Bellwood $O$, Choat $H$, Saxena $N$ (eds) Recent advances in marine science 94. PACON 94. PACON International and James Cook University of North Queensland, Townsville, p 95-105

Church JA (1987) East Australian Current adjacent to the Great Barrier Reef. Aust J mar Freshwat Res 38:671-683

Dight IJ, James MK. Bode L (1990) Modelling the larval dispersal of Acanthaster planci. II. Patterns of reef connectivity. Coral Reefs 9(3): 125-134

Farrell TM. Bracher D, Roughgarden J (1991) Cross-shelf transport causes recruitment to intertadal populations in central California. Limnol Oceanogr 36:279-288

Goodrich DM, van Montfrans J, Orth RJ (1989) Blue crab megalopal influx to Chesapeake Bay: evidence for a winddriven mechanism. Estuar coast Shelf Sci 29:247-260

Jenkins GP, Black KP (1994) Temporal variability in settle- ment of a coastal fish, the King George whiting, Sillaginodes punctata, is determined by low-frequency hydrodynamics. Limnol Oceanogr 39(7):1744-1754

Kenchungton RA (1977) Growth and recruitment of Acanthaster planci (L.) on the Great Barrier Reef. Biol Conserv 11:103-118

Lassig BR, Kelleher G (1992) Crown-of-thorns starfish on the Great Barrier Reef. Environmental research in Australia: case studies. Australian Government Publishing Service, Canberra (Australian Science and Technology Council), p $39-62$

Little KT, Epifanio CE (1991) Mechanism for the re-invasion of an estuary by two species of brachyuran megalopae. Mar Ecol Prog Ser 68:235-242

Lucas JS (1973) Reproductive and larval biology of Acanthaster planci in Great Barrier Reef waters. Micronesica 9:197-203

McCallum H (1992) Completing the cycle: stock-recruitment relationships and Acanthaster. Aust $\mathrm{J}$ mar Freshwat Res 43:137-146

Moran PJ (1986) The Acanthaster phenomenon. Oceanogr mar Biol A Rev 24:379-480

Moran PJ, Bradbury RH, Reichelt RE (1985) Mesoscale studies of the crown-of-thorns/coral interaction: a case history from the Great Barrier Reef. Proc 5th int Coral Reefs Congr 5:321-6

Moran PJ, Bradbury RH, Reichelt RE (1988) Distribution of recent outbreaks of the crown-of-thorns starfish (Acanthaster planci) along the Great Barrier Reef: 1985-1986 Coral Reefs 7:125-137

Moran PJ, De'ath G (1992) Suitability of the manta tow technique for estimating relative and absolute abundances of crown-of-thorns starfish (Acanthaster planci L.) and corals. Aust J mar Freshwat Res 43:357-78

Moran PJ, De'ath G, Baker VJ, Bass DK, Christie CA, Miller IR, Miller-Smith BA, Thompson AA (1992) Pattern of outbreaks of crown-of-thorns starfish (Acanthaster planci L.) along the Great Barrier Reef since 1966. Aust J mar Freshwat Res 43:39-52

Olson RR (1987) In situ culturing as a test of the larval starvation hypothesis for the crown-of-thorns starfish. Acanthaster planci. Limnol Oceanogr 32:895-904

Olson RR, Olson MH (1989\} Food Iimitation of planktonic marine invertebrate larvae: does it control recruitment success? A Rev Ecol Syst 20: 225-247

Reichelt RE, Bradbury RH, Moran PJ (1990) Distribution of Acanthaster planci outbreaks on the Great Barrier Reef between 1966 and 1989. Coral Reefs 9:97-103

Roughgarden J, Gaines SD, Possingham H (1988) Recruitment dynamics in complex life cycles. Science 241. $1460-1466$

Stevens A, Hatton D, Black K (1992) Green Island current meter measurements in June and November 1991 Victorian Institute of Marine Sciences, Working Paper No 26 , Melbourne

Wolanski E (1994) Physical oceanographic processes of the Great Barrier Reef. CRC Marine Science Series, Boca Raton, p 81

Zann LP, Brodie J, Vuki V (1990) History and dynamics of the crown-of-thorns starfish Acanthaster planci (L.) in the Suva area, Fiji. Coral Reefs 9:134-144

Zann LP, Moran PJ (1988) A coordinated research program on the Acanthaster phenomenon on the Great Barrier Reef. Proc 6th int Coral Reefs Symp 2:177-182

Manuscript first received: June 29, 1994

Revised version accepted: March 8, 1995 